control may successfully lower fibrinogen concentration. But this still leaves a difficult question: given the many sources of variation, is a single measurement of fibrinogen concentration of any practical value?

S J MACHIN Professor

IJ MACKIE Lecturer

Department of Haematology,

University College London Medical School,

London WC1E 6HX

1 Ernst E. Fibrinogen-an independent risk factor for cardiovascular disease. BMF 1991;303:596-7. 2 Ernst E, Koenig W, Lowe GDO, Meade TW. Fibrinogen: a "new" cardiovascular risk factor. Vienna: Blackwell-MZV, 1992.
3 Meade TW, Mellows S, Brozovic M, Miller GJ, Chakrabarti RA, North WR, et al. Haemostatic function and ischaemic heart disease. Principal results of the Northwick Park heart study. Lance 1986;ii:533-7.

4 Kannel WB, Wolfe PA, Castelli WP, D'Agostino RB. Fibrinogen and risk of cardiovascular disease: the Framingham study. $\mathcal{F} A M A$ 1987;258:1183-6.

5 Clauss A. Rapid physiological coagulation method in determination of fibrinogen. Acta Haemato 1957;17:237-40.

6 Natelson EA, Dooley DF. Rapid determination of fibrinogen by thrombokinetics. Am $\mathcal{f}$ Clin Pathol 1974;61:828-33.

7 Zondag ACP, Kolb AM, Muller AD. Simple screening techniques for the detection of hypercoagulation. Haemostasis 1984;14:445-9.

8 Whicher JT, Dieppe PA. Acute phase proteins. Clin Immunol Allergy 1985;5:425-46.

9 Meade TW, Chakrabarti R, Haines AP, North WR, Stirling Y. Characteristics affecting

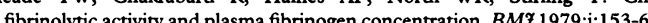

10 Cohen H, Mackie IJ, Walshe K, Gillmer MDG, Machin SJ. A comparison of the effects of two triphasic oral contraceptives on haemostasis. Br f Haematol 1988;69:259-63.

11 Inglis TCN, Stuart J, George AJ, Davies AJ. Haemostatic and rheological changes in normal Inglis TCN, Stuart J, George AJ, Davies AJ. Haemostatic
pregnancy and pre-eclampsia. Brf Haematol 1982;50:461-5.

12 Lee AJ, Lowe GDO, Smith WCA, Tunstall-Pedoe H. Plasma fibrinogen in women: relationship with oral contraception, the menopause and hormone replacement therapy. $\mathrm{Br} f$ Haematol 1993;83:616-21

\title{
Antiphospholipid syndrome
}

\section{A common cause of thrombosis}

Ten years have elapsed since our original description of the anticardiolipin syndrome, comprising arterial and venous thrombosis, strokes, migraine, livedo reticularis, recurrent abortion, and occasional thrombocytopenia. ${ }^{1}$ Other features of what is now widely known as the antiphospholipid syndrome are labile hypertension, chorea, epilepsy, amaurosis fugax, myelitis, early myocardial infarction, valvular heart disease, the Budd-Chiari syndrome, haemolytic anaemia, adrenal infarction, and Addison's disease. ${ }^{2}$

The anticardiolipin test, which has been internationally standardised, ${ }^{3}$ has become a critical factor in identifying patients with the syndrome. Most patients with clinical thrombotic problems have persistent moderate to high titres of IgG antibodies to cardiolipin (a phospholipid). A few, however, have raised titres only of IgM antibodies.

The syndrome's overriding association is with thrombosis, both venous and arterial; its association with arterial thrombosis distinguishes it from many other hypercoagulation disorders. Vessels of all sizes may be affected, and the vascular pathological appearance has consistently been of bland occlusion without inflammatory infiltrate. ${ }^{4}$ The antibodies themselves persist for many years, possibly a lifetime. Thus one of the key clinical questions is what additional factors lead to the sudden development of thrombosis.

Cerebral ischaemia is by far the most important neurological manifestation of the antiphospholipid syndrome. ${ }^{5}$ Although the cerebral disease is likely to result from widespread thrombosis of small (and sometimes large) cerebral vessels, other mechanisms may contribute. In a prospective echocardiographic study of 132 patients with systemic lupus erythematosus valvular lesions were relatively commonmore so in patients with antibodies to phospholipids. ${ }^{6}$ Another study, designed to investigate the relation between antibodies to phospholipid and strokes, found that one third of patients who experienced strokes and had raised titres of antibodies to cardiolipin had abnormal echocardiograms. ${ }^{7}$ In some patients untreated recurrent cerebral infarcts have led to multi-infarct dementia. Behavioural disorders, psychiatric disturbance, and epilepsy may well come to be recognised as an important feature of the syndrome, possibly hitherto underreported. ${ }^{2}$

The association between antibodies to cardiolipin and recurrent spontaneous abortion is one of the most consistent features of the syndrome. The rate of miscarriage in patients with antibodies to phospholipid is high. ${ }^{8}$ The prevalence of the antibodies in women with recurrent spontaneous abortion may be as high as one in five, ${ }^{9}$ and, increasingly, testing for the antibodies is becoming routine in women with recurrent miscarriages. The mechanism is thought to be a progressive thrombosis of the microvasculature of the placenta, and in pregnancies that go beyond mid-term a progressive fall off in fetal circulation can be shown with Doppler flow studies. ${ }^{10}$

Clinical experience suggests that among patients with raised antibody titres to phospholipid there are subsets with varying thrombotic risk. This concept is of key importance because it suggests that the current antibody assays detect a heterogeneous group of antibodies and only a particular subset is associated with the thrombotic syndrome..$^{112}$

The mechanism of thrombosis is unknown. Recent studies have shown that a subset of antibodies to phospholipid reacts with the complex of phospholipid and the serum protein $\beta_{2}$ glycoprotein 1 , the so called cofactor which inhibits factor XII activation, platelet activation, and prothrombinase activity. ${ }^{13}$ Interference with these properties might provide a potent way in which antibodies to phospholipid could predispose to a prothrombotic diathesis.

The mechanism(s) responsible for the induction of antibodies to phospholipid remain an enigma. Recently, Gharavi and colleagues showed that, although pure phospholipids are not immunogenic, immunisation with purified $\beta_{2}$ glycoprotein 1 resulted in the production of antibodies to cardiolipin. ${ }^{14}$ This work suggests that phospholipid binding protein may be the key immunogen.

The discovery of the antiphospholipid syndrome has provided new insights for treatment. Low dose aspirin $(75 \mathrm{mg}$ a day), possibly in addition to subcutaneous heparin in those with a history of thrombosis, is a logical first line of treatment and is improving the success rate in pregnant women who are positive for the antibody. ${ }^{1516}$ Little doubt now exists that patients with high titres of antibodies to phospholipid and previous major thromboses require long term, possibly lifelong anticoagulation, and in these patients international normalised ratios have to be kept around $3 .{ }^{17}$ Steroids and immunosuppressive drugs to reduce antibody titres have not provided long term benefit.

The recognition that antibodies to phospholipid are associated with a distinct syndrome, including arterial and venous thrombosis, has opened up new avenues for treatment and research. Whether the pathogenetic effects of the antibodies are on platelets, endothelial cells, or clotting 
mechanisms there is no doubt that an important thrombotic mechanism has now been defined.

\section{MUNTHER A KHAMASHTA} Deputy director

GRAHAM R V HUGHES Director

Lupus Arthritis Research Unit,

Rayne Institute,

St Thomas's Hospital,

London SE1 7EH

1 Hughes GRV. Thrombosis, abortion, cerebral disease, and the lupus anticoagulant. $B M f$ 1983;287:1088-9.

2 Hughes GRV. The antiphospholipid syndrome: ten years on. Lancet 1993;342:341-4.

3 Khamashta MA, Hughes GRV. Detection and importance of anticardiolipin antibodies. 7 Clin Pathol 1993;46:104-7.

4 Lie JT. Vasculopathy in the antiphospholipid syndrome: thrombosis or vasculitis, or both? $f$ Rheumatol 1989;16:713-5.

5 Montalban J, Codina A, Ordi J, Vilardell M, Khamashta M, Hughes GRV. Antiphospholipid antibodies in cerebral ischemia. Stroke 1991;22:750-3.

6 Khamashta MA, Cervera R, Asherson RA, Font J, Gil A, Coltart PJ, et al. Association of antibodies against phospholipids with heart valve disease in systemic lupus erythematosus. Lancet 1990;335:1541-4.

7 Antiphospholipid Antibodies in Stroke Study Group. Clinical and laboratory findings in patients with antiphospholipid antibodies and cerebral ischemia. Stroke 1990;21:1268-73.

8 Ginsberg JS, Brill-Edwards P, Johnston M, Denburg JA, Andrew M, Burrows RF, et al. Relationship of antiphospholipid antibodies to pregnancy loss in patients with systemic lupus Relationship of antiphospholipid antibodies to pregnancy loss
erythematosus: a cross-sectional study. Blood 1992;80:975-80.

9 Unander AM, Norberg R, Hahn L, Arfors L. Anticardiolipin antibodies and complement in ninety-nine women with habitual abortion. Am $\mathcal{f}$ Obstet Gynecol 1987;156:114-9.

10 Kerslake S, Morton KE, Versi E, Buchanan NMM, Khamashta MA, Baguley E, et al. Early Doppler studies in lupus pregnancy. Am f Reprod Immunol 1992;28:172-5.

$11 \mathrm{McNeil}$ HP, Hunt JE, Krilis SA. Antiphospholipid antibodies-new insights into their specificity and clinical importance. Scand $\mathcal{F}$ Immunol 1992;36:647-52.

12 Bevers EM, Galli M. Co-factors involved in the antiphospholipid syndrome. Lupus 1992;1:51-3.

13 McNeil HP, Simpson RJ, Chesterman CN, Krilis SA. Antiphospholipid antibodies are directed against a complex antigen that includes a lipid-binding inhibitor of coagulation: $\beta_{2} 1$ (apolipoprotein H). Proc Natl Acad Sci USA 1990;87:4120-4.

14 Gharavi AE, Sammaritano LR, Wen J, Elkon KB. Induction of antiphospholipid autoantibodies by immunisation with $\beta_{2}$ glycoprotein 1 (apoliprotein $H$ ). 7 Clin Invest 1992;90:1105-9.

15 Elder MG, DeSwiet M, Robertson A, Elder MA, Flloyd E, Hawkins DF. Low-dose aspirin in pregnancy. Lancet 1988;i:410.

16 Cowchock FS, Reece EA, Balaban D, Branch DW, Plouffe L. Repeated fetal losses associated with antiphospholipid antibodies. A collaborative randomised trial comparing prednisone with low-dose heparin treatment. Am f Obstet Gynecol 1992;166:1318-23.

17 Rosove MH, Brewer PMC. Antiphospholipid thrombosis: clinical course after the first thrombotic event in 70 patients. Ann Intern Med 1992;117:303-8.

\title{
Electromagnetic fields and childhood cancer
}

\author{
No causal relation has been established
}

The possibility that exposure to electromagnetic fields causes cancers, including childhood cancers, is one of continuing public concern and scientific debate. The subject has been reviewed on several occasions, most recently and comprehensively by an advisory group set up by Britain's National Radiological Protection Board (NRPB). ${ }^{1}$ This group considered four types of exposure: occupational; residential exposure from electrical power lines and domestic wiring (including eight case-control studies of childhood cancer); exposure from electrical appliances (including two casecontrol studies of childhood cancer); and paternal occupational exposure in relation to cancer in the offspring (six case-control studies-three of central nervous system tumours and three of neuroblastoma).

For the two studies relating to electrical appliances the NRPB group concluded that "these results are incapable of interpretation" (because of the possibility of recall bias and uncertainty about whether the controls were representative). For the studies of parental exposure they concluded that those relating to neuroblastoma did not suggest any relation to parental exposure and that though such a relation might exist in the case of central nervous system tumours, no definite conclusion could be reached.

The eight case-control studies concerned with a possible relation between childhood cancer and residential exposure from power lines and domestic wiring varied greatly in methodology and, particularly, the measure of exposure used: direct measurements of magnetic fields were available for only three of these studies; some based assessments of exposure on classification of electrical wiring configurations. The NRPB group commented that "wire configurations have shown a stronger relationship to childhood cancer than other measures of electromagnetic field exposure."

It suggested that the explanation for this relation might be that these measures provide a better assessment of long term exposure but that, alternatively, types of wiring configuration might be associated with other characteristics of the house concerned and the apparent association with cancer might be an indirect one-that is, might be due to confounding. Jones et al have suggested that such an association might arise through selection bias as between cases and controls rather than through confounding. ${ }^{2}$ For these eight case-control studies the NRPB report concluded that "taken at face value they appear to provide some weak evidence in support of the postulated association, which is less weak for brain cancer than for leukaemia." The advisory group commented on the difficulty of accepting the evidence in view of the problems with selection of control subjects.

Since the NRPB report three further studies of this type have appeared. Two of these, from Denmark ( $p$ 891 $)^{3}$ and Finland (p 895 $)^{4}$ appear in this issue of the $B M \mathcal{F}$ and a third, from Sweden, ${ }^{5}$ has apparently not yet been published in a readily accessible form. (Of the eight earlier studies, seven are listed by Olsen et al (their references 1-7) and the eighth appears to be available only as an abstract. ${ }^{6}$ )

Do the three new studies give reason to modify the "extreme caution" advocated by the NRPB group in assessing the previous studies? All three studies use calculations of magnetic fields and the two case-control studies use carefully selected controls ${ }^{35}$; the third is a cohort study, ${ }^{4}$ so the problem of control selection does not arise. The two case-control studies show some positive relations between exposure to magnetic fields and the incidence of childhood cancer, though the numbers of exposed cases are small. The findings of the cohort study are essentially negative, particularly when allowance is made for the fact that the one positive finding is partly accounted for by the occurrence of three tumours in a boy with neurofibromatosis.

In the Danish case-control study the strongest effect is found in relation to a grouping of exposure categories chosen after examination of the data, though the analysis is adjusted for this. ${ }^{3}$ In addition, as the authors point out, it is puzzling that the effect is significant when average exposure for periods of residence close to the power lines is used but not when cumulative dose is used. In the Swedish study ${ }^{5}$ there is some evidence for a relation with childhood leukaemia but no association was found for brain tumours, the type of childhood tumour for which the NRPB group previously found the evidence least weak.

The possibility that magnetic fields associated with electricity transmission may cause some cases of childhood cancer cannot be dismissed, but the lack of consistency among published studies, and the absence of an accepted biological explanation for such a relation, means that we have to 